\title{
A PERSEGUIÇÃO AO POVO ROHINGYA E O DESRESPEITO AOS DIREITOS HUMANOS EM MYANMAR
}

\author{
MARCELLA LINS ${ }^{1}$ \\ KARINA VICTOR FERRARIA ${ }^{2}$
}

\begin{abstract}
Resumo: O presente material se configura como um estudo de caso da perseguição sofrida pelo povo Rohingya no estado de Myanmar. Historicamente oprimidos pela máquina estatal e marginalizados pela maioria da população birmanesa, investiga-se neste artigo as razões e motivações dessa perseguição e os embasamentos legais para sua condenação, tomando por base o relatório sobre o assunto do Conselho de Direitos Humanos das Nações Unidas, a Declaração Universal dos Direitos Humanos e a normativa e órgãos internacionais vigentes no regime internacional de direitos humanos. Em última instância, traçam-se perspectivas para a resolução do conflito a partir de dois caminhos: a intervenção da ASEAN e a secessão do território Rohingya, vista sobre uma ótica aus tro-libertária.
\end{abstract}

Palavras-chave: Direitos Humanos; Myanmar; Rohingyas.

Os Rohingyas são uma das minorias étnicas, linguísticas e religiosas do estado ${ }^{3}$ Rakhine do Norte de Myanmar, um país caracterizado pela multiculturalidade de sua população, incluindo mais de 100 grupos étnicos diferentes. A preponderância do budismo no país, representando $87,9 \%$ da população, enquanto os cristãos representam $6,2 \%$ e os islâmicos $4,3 \%$, cria condições para a utilização da religião como um instrumento segregador entre os diferentes grupos. Essas características acarretaram conflitos étnico-religiosos ao longo dos sécu-

\footnotetext{
1 Graduada em Relações Internacionais pela Universidade Anhembi Morumbi. marcella.lins@outlook.com

2 Graduada em Relações Internacionais pela Universidade Anhembi Morumbi. karinaferraria@gmail.com

3 Neste artigo, opta-se pela utilização da grafia "estado", com "e” minúsculo, ao invés da grafia "Estado", com "E” maiúsculo, sugerida pela norma culta, de maneira a contribuir para a deslegitimação da ideia do estado como uma entidade quase divina que está acima dos indivíduos.
} 
A perseguição ao povo Rohingya e o desrespeito aos direitos humanos em Myanmar

los, especialmente após o período colonial britânico - século XIX -, em que o novo governo independente falhou em construir uma unidade e identidade nacionais (AZAD; JASMIN, 2013).

O presente artigo tem por objetivo analisar a perseguição ao povo Rohingya no estado de Myanmar, sua marginalização na sociedade birmanesa e como essas ações acarretam o desrespeito aos direitos humanos do grupo. Para efeito de tal propósito, a primeira seção do texto aborda a construção histórica da perseguição estatal ao povo Rohingya. Nas duas seçóes seguintes, são pormenorizados alguns artigos da Declaração Universal de Direitos Humanos, demonstrando, com exemplos empíricos, como são desrespeitados no país, e é avaliado o marco jurídico internacional em que se enquadra a situação em Myanmar e quais ações podem ser tomadas nesse âmbito. Finalmente, discutem-se as perspectivas de resolução do conflito com duas principais vertentes de análise: a possibilidade de intervenção da ASEAN e a secessão do território Rohingya, vista sobre uma ótica austro-libertária.

INSTITUCIONALIZAÇÃO DA PERSEGUIÇÃO

A concepção étnica atual do estado de Myanmar é relativamente moderna. Fruto da colonização britânica, se intensificou a partir de 1962, quando os militares assumiram o poder com um projeto de "burmificação", isto é, a construção de uma nação homogênea e unitária, a partir da assimilação da cultura Bamar ${ }^{4}$ (FARZANA, 2017).

O acordo de Panglong de 1947 e a criação de divisóes administrativas por etnias em 1974, revelam que o projeto de construção política do país tem o reconhecimento étnico como indispensável. Dito isso, verifica-se um processo de recriação da narrativa histórica em Myanmar, tanto dos Bamar quanto dos próprios Rohingyas, com o objetivo de reivindicar o controle sobre a região de Rakhine do Norte (LEIDER, 2015).

Há controvérsias no que diz respeito à origem dos Rohingyas. Autores como $\mathrm{Ba}$ Tha remetem a origem do grupo à árabes que teriam visitado a região ainda no século XI, an tes mesmo dos budistas ocuparem o território (LEIDER, 2015). Leider (2015), em contrapar-

\footnotetext{
$4 \quad$ Apesar de ser possível encontrar na literatura o termo "birmaneses" ou "Burma (em inglês)" para se referir à etnia majoritária na região de Myanmar, será utilizado, nesse artigo, o termo mais aceito "Bamar” para identificar o grupo étnico em questão. O termo "birmaneses”, por sua vez, será utilizado como adjetivo pátrio da República da União de Myanmar.
} 
tida, afirma que o grupo na verdade representa uma tentativa dos muçulmanos de Rakhine do Norte de construírem uma identidade comum em busca da autonomia política. Essa seria a estratégia considerada mais adequada pelo grupo de maneira a combater o processo de "burmificação". Independente das interpretações históricas, o fato é que os muçulmanos desta região têm sofrido com a perseguição por parte dos Bamar e do próprio governo de Myanmar há décadas.

A região que hoje se conhece como o estado de Myanmar fez parte do Império Britânico nos séculos XIX e XX. Após enfrentar três guerras contra os Bamar, instituíram controle absoluto sobre o território em 1885 e iniciaram, dessa maneira, campanhas de pacificação para estabilização da ordem e segurança, já que enxergavam a área como selvagem e sem lei. O mapeamento do território apresentou diversos grupos étnicos na região, como explicado por Guan (2007, p. 125): "Pre-colonial Burma was never a unified and coherent state in the way we understand the features of modern state today”.

A solução encontrada pela Coroa para sujeitar essas etnias a viverem sob uma mesma administração colonial foi a estratégia de "dividir e governar” (ALAM, 2019). Basicamente, criaram a ideia de "fronteiras étnicas" (FARZANA, 2017), ao estabelecerem o centro do país, onde vivia o grupo majoritário Bamar, como núcleo e os entornos excluídos habitados pelas minorias étnicas como periferia. O Império passou a exercer domínio direto na região central acabando com a organização política e social tradicional, enquanto na periferia foi concedida maior autonomia, preservando suas estruturas (ALAM, 2019). Primeiramente, os britânicos exerceram seu domínio por meio da Índia e em 1937 concederam à região da Birmânia a condição de território "autônomo”, tendo a própria estrutura colonial política.

Devido à resistência Bamar durante as guerras de conquista, os britânicos não confiavam neste grupo, por isso as limitadas vagas para os nativos na administração colonial e no exército eram concedidas aos grupos minoritários (MUKHERJEE, 2019). A exclusão da maioria étnica levou à construção de um forte sentimento nacionalista, baseado no budismo, característico entre os membros do grupo.

A luta pela independência se inicia em 1941 com um braço militar do movimento nacionalista Bamar. Os “The Thirty Comrades”, liderado por Aung San, se tornaram o centro do exército de libertação, se alinhando aos japoneses, que se encontravam em pleno processo de expansionismo. No começo da Segunda Guerra Mundial, enquanto os Bamar apoiavam as potências do Eixo, minorias étnicas apoiavam os britânicos e os Aliados. Os Rohingyas, por exemplo, queriam manter sua relativa autonomia e, também, foi-lhes prometida 
A perseguição ao povo Rohingya e o desrespeito aos direitos humanos em Myanmar

a criação de um território autônomo no estado do Arakan. Por esse apoio à metrópole ficaram estigmatizados como anti-birmânicos (ALAM, 2019).

Com o fim da guerra, o enfraquecimento das metrópoles europeias e a eclosão dos ideais emancipatórios, o movimento de Aung San obteve êxito libertando a Birmânia do pacto colonial em 1948. A princípio, Aung San firmou um documento com líderes de diferentes grupos étnicos reconhecendo sua autonomia e estabelecendo um compromisso para o estabelecimento de um país livre, mantendo as fronteiras delimitadas pelo Império Britânico. Seu sucessor U Nu buscou adaptar essa política conciliatória à sua obsessão com a ideia de utilizar o budismo como fator chave para a criação de uma identidade nacional (MUKHERJEE, 2019).

Nesse ínterim, foi estabelecida a "Union Citizenship Law" que identificou oito etnias específicas como nativas da Birmânia. Os Rohingyas foram excluídos dessa definição, no entanto, havia a possibilidade de obterem a nacionalidade do país se suas famílias vivessem na região há duas ou mais geraçôes (ALAM, 2019).

As propostas de concessão de autonomia para os grupos periféricos foram interpretadas pelos militares como ameaças de desestabilização da ordem e dissolução territorial. Em 1962, liderados pelo general Ne Win, as forças armadas - Tatmadaw -, motivadas pelo desejo de se consolidarem como state-builders, deram um golpe militar socialista, de cunho nacionalista budista. O general Ne Win, primeiramente, engendrou uma lista definindo 135 grupos étnicos nacionais, excluindo a população Rohingya. Não há, no entanto, indícios claros de como essa lista foi estabelecida (CHEESMAN, 2017).

A junta militar instituiu, também, a política dos “Four Cuts", em que foram cortados suplementos - comida, inteligência, recursos financeiros e recrutas - de grupos étnicos armados que se opunham ao novo governo. Essa política tinha por objetivo amedrontar a população civil, evitando que se unissem a esses grupos (SCHERF; GONZALEZ, 2018). Além disso, expropriaram escolas privadas, baniram escolas inglesas e fecharam bibliotecas administradas por outros países, em busca de um resgate do tradicionalismo em oposição à influência ocidental, tida como colonialista (MUKHERJEE, 2019)

Em 1982, uma nova lei de nacionalidade foi promulgada baseada no princípio de jus sanguini ${ }^{5}$. A "Union Citizenship Act" definia que existiam três grupos detentores do direi-

5 Nacionalidade obtida de acordo com a filiação. Ao nascer, o indivíduo herda a nacionalidade de seus progenitores podendo repassá-la, posteriormente, para seus descendentes. Neste caso, não há concessão de nacionalidade de acordo com o local de nascimento do indivíduo (jus solis). 
to à nacionalidade birmanesa, derivados da lista das 135 etnias oficiais. Os Rohingyas dificilmente se enquadravam nesses grupos, tendo sua nacionalidade negada, ainda que pudessem, em certos casos, demandar processos de naturalização (ALAM, 2019).

Após diversos abusos cometidos pelo governo militar com relação à supressão de direitos civis e políticos, de maneira a justificar a centralização do poder nas mãos do Tatmadaw, além das desastrosas reformas econômicas que isolaram o país e aumentaram a pobreza, em 1988 eclodiram diversas manifestações populares pró-democráticas. O resultado do movimento foi a vitória do "National League for Democracy" - NLD - nas eleições gerais de 1990. Sem embargo, este não assumiu o poder, uma vez que os militares haviam estabelecido, ainda em 1988, o Conselho do Estado de Restauração da Lei e da Ordem, recusando-se a aceitar o resultado das eleições (HUMAN RIGHTS COUNCIL, 2018)

Ainda nos anos 1990 houve um grande fluxo de deslocamento de Rohingyas em direção à Bangladesh. Entre 1991 e 1992 cerca de 300 mil refugiados foram forçados pelas au toridades militares a abandonar suas casas e cruzar a fronteira (ALAM, 2019). A ação das for ças armadas foi importante para retomar o apoio da maior parte da população, de certa forma perdido em 1988, ao apelar para um discurso nacionalista, populista e antimuçulmano.

Em 2008, uma nova constituição foi adotada. Projetada pelos militares para garantir seu domínio político e, ao mesmo tempo, evitar pressóes como na década de 1980, ela também garantiu a exclusão definitiva dos Rohingyas da sociedade, uma vez que estabeleceu critérios de nacionalidade que privilegiavam determinados grupos étnicos, enquanto excluía outros rigorosamente (ALAM, 2019). A Constituição de Myanmar, a princípio, assemelha-se às mais modernas em termos de garantia do bem-estar da população e do respeito aos direitos humanos, no entanto, a inserir o conceito de "Raças Nacionais" e delimitar estritamente a concessão de cidadania, deixa claro que esses direitos são limitados.

As eleições de 2010 marcaram a transição do regime militar para uma democracia civil, ainda que a constituição assegure uma parcela de poder às forças armadas, como a garan tia da participação dos Serviços de Defesa na composição do parlamento (REPUBLIC OF THE UNION OF MYANMAR, 2008, Chapter 4, Art.74). Já em 2011, um processo de liberalização política foi proposto pelo presidente Thein Sein, buscando maior participação política popular e desenvolvimento econômico.

O novo governo estabeleceu um cessar-fogo com diversos grupos armados étnico minoritários no país, além de reforçar seu desejo de construir uma política nacional de diálogo (WALTON; HAYWARD, 2014). Apesar desses avanços relativos, o governo de Thein Sein manteve a retórica Bamar ao considerar o povo Rohingya como estrangeiro, defendendo o re- 
assentamento dessa população em outro país e obtendo respaldo de monges budistas, assim como de grande parte da população birmanesa (KIPGEN, 2013).

Os Bamar, protegidos e privilegiados pela constituição, externalizaram uma forte retórica nacionalista antimuçulmana como resposta às reformas propostas por Sein, criando grupos extremistas, como o "969 Movement" e o "Patriotic Association of Myanmar" - MaBaTha - (HUMAN RIGHTS COUNCIL, 2018). Monges budistas, como U Wirathu, desempenham um importante papel na divulgação dessa retórica, alegando, como em outras oportunidades ao longo da história, que a sobrevivência da religião e do estado está ameaçada pela crescente influência islâmica (WALTON; HAYWARD, 2014).

Um incidente em 2012 deu início à perseguição sistêmica e institucionalizada à minoria Rohingya como vemos hoje. Após o estupro e o assassinato de uma jovem budista, supostamente por dois homens islâmicos, uma multidão Bamar assassinou dez muçulmanos escolhidos ao azar. Desde então, a violação de direitos humanos sofreu uma escalada, atingindo seu ápice em 2017, quando o Tatmadaw iniciou a operação clearence em resposta ao ataque do "Arakan Robingya Salvation Army" a uma de suas bases e a alguns postos policiais. A resposta das forças armadas foi completamente desproporcional: civis inocentes foram vítimas de violência sexual, trabalho forçado, prisões arbitrárias e tratamento desumano, e um novo fluxo de deslocamento foi gerado (ALAM, 2019).

A participação direta dos militares, a incitação de atitudes violentas da população por monges budistas e a negligência do governo em relação às constantes violações de direitos humanos, bem como a exclusão gradual dos Rohingyas como cidadãos birmaneses, os levou à condição de apátridas e de párias da sociedade birmanesa. Hoje, os membros dessa população vivem em uma região previamente demarcada - norte do estado de Rakhine -, isolados do restante dos habitantes e impedidos legalmente de sair desse local. Existem também políticas de controle de natalidade e a imposição de autorização para casamentos, entre outras violações aos direitos humanos que serão abordadas no próximo tópico. 
Uma tabela ${ }^{6}$ foi elaborada de maneira a exemplificar a subtração dos direitos básicos da população Rohingya. Assim, na primeira coluna se encontram alguns artigos da Declaração Universal dos Direitos Humanos (ASSEMBLEIA GERAL DAS NAÇÕES UNIDAS, 1948) e na segunda coluna é justificado como esses artigos são desrespeitados em Myanmar, tendo como base o relatório do Conselho de Direitos Humanos das Nações Unidas (HUMAN RIGHTS COUNCIL, 2018) acerca do assunto:

\begin{tabular}{|c|c|}
\hline $\begin{array}{l}\text { Artigos da DUDH (ASSEMBLEIA GERAL DAS NA- } \\
\text { ÇÖES UNIDAS, 1948) }\end{array}$ & $\begin{array}{l}\text { Provas de violação (HUMAN } \\
\text { COUNCIL, 2018) }\end{array}$ \\
\hline $\begin{array}{l}\text { "Art. } 3 \text { - Todo ser humano tem direito à vida, à liberdade e } \\
\text { à segurança pessoal (...). " }\end{array}$ & \multirow{4}{*}{$\begin{array}{l}\text { Imposições de toque de recolher, a proibição do } \\
\text { direito de livre circulação por espaços além dos } \\
\text { definidos pelo estado e a instituição de trabalhos } \\
\text { forçados. }\end{array}$} \\
\hline $\begin{array}{l}\text { "Art. } 12 \text { - Ninguém será sujeito à interferência em sua vida } \\
\text { privada, em sua família, em seu lar ou em sua correspon- } \\
\text { dência, nem a ataque à sua honra e reputação. Todo ser } \\
\text { humano tem direito à proteção da lei contra tais interfe- } \\
\text { rências ou ataques (...)." }\end{array}$ & \\
\hline $\begin{array}{l}\text { "Art. } 13 \text { - Todo ser humano tem direito à liberdade de lo- } \\
\text { comoção e residência dentro das fronteiras de cada estado } \\
\text { (...)." }\end{array}$ & \\
\hline $\begin{array}{l}\text { "Art. } 23 \text { - Todo ser humano tem direito ao trabalho, à livre } \\
\text { escolha de emprego, a condiçôes justas e favoráveis de tra- } \\
\text { balho e à proteção contra o desemprego." }\end{array}$ & \\
\hline $\begin{array}{l}\text { "Art. } 5 \text { - Ninguém será submetido à tortura nem a trata- } \\
\text { mento ou castigo cruel, desumano ou degradante (...)." }\end{array}$ & \multirow{2}{*}{$\begin{array}{l}\text { Prisões arbitrárias e tratamento desumano, in- } \\
\text { cluindo tortura, nas cadeias e centros de deten- } \\
\text { ção. }\end{array}$} \\
\hline $\begin{array}{l}\text { "Art. } 9 \text { - Ninguém será arbitrariamente preso, detido ou } \\
\text { exilado." }\end{array}$ & \\
\hline $\begin{array}{l}\text { "Art. } 7 \text { - Todos são iguais perante a lei e têm direito, sem } \\
\text { qualquer distinção, a igual proteção da lei. (...)." }\end{array}$ & \multirow{2}{*}{$\begin{array}{l}\text { Privação por parte do estado do acesso dessa po- } \\
\text { pulação à comida, saúde e educação adequados, } \\
\text { ou seja, condiçóes mínimas de vida. Além de } \\
\text { açôes do estado categorizadas como limpeza ét- } \\
\text { nica, incluindo o assassinato de mais de } 10.000 \\
\text { Rohingya e estupros coletivos de mulheres e cri- } \\
\text { anças pelas forças armadas. }\end{array}$} \\
\hline $\begin{array}{l}\text { "Art. } 21 \text { - Todo ser humano tem igual direito de acesso ao } \\
\text { serviço público do seu país." }\end{array}$ & \\
\hline $\begin{array}{l}\text { 'Art. } 15 \text { - Ninguém será arbitrariamente privado de sua } \\
\text { nacionalidade, nem do direito de mudar de nacionalidade. } \\
\text { " }\end{array}$ & $\begin{array}{l}\text { Proibição da concessão de nacionalidade birma- } \\
\text { nesa. }\end{array}$ \\
\hline $\begin{array}{l}\text { 'Art. } 16 \text { - Os homens e mulheres de maior idade, sem qual- } \\
\text { quer restrição de raça, nacionalidade ou religião, têm o di- } \\
\text { reito de contrair matrimônio e fundar uma família. Go- } \\
\text { zam de iguais direitos em relação ao casamento, sua dura- }\end{array}$ & $\begin{array}{l}\text { Necessidade de autorização estatal para contrair } \\
\text { matrimônio. }\end{array}$ \\
\hline
\end{tabular}


A perseguição ao povo Rohingya e o desrespeito aos direitos humanos em Myanmar

\begin{tabular}{|c|c|}
\hline ção e sua dissolução." & \\
\hline $\begin{array}{l}\text { "Art. } 17 \text { - Ninguém será arbitrariamente privado de sua } \\
\text { propriedade." }\end{array}$ & $\begin{array}{l}8.000 \text { casas de Rohingyas destruídas em um ano } \\
\text { (2012-2013) e restriçốes para a aquisição de pro- } \\
\text { priedade. }\end{array}$ \\
\hline $\begin{array}{l}\text { "Art. } 18 \text { - Todo ser humano tem direito à liberdade de } \\
\text { pensamento, consciência e religião; este direito inclui a li- } \\
\text { berdade de mudar de religiáo ou crença e a liberdade de } \\
\text { manifestar essa religião ou crença, pelo ensino, pela práti- } \\
\text { ca, pelo culto e pela observância, em público ou em parti- } \\
\text { cular (...)." }\end{array}$ & \multirow{3}{*}{$\begin{array}{l}\text { Proibição da reunião entre } 5 \text { ou mais pessoas e } \\
\text { assim, consequentemente, a proibiçãa de cultos } \\
\text { religiosos em mesquitas. }\end{array}$} \\
\hline $\begin{array}{l}\text { "Art. } 19 \text { - Todo ser humano tem direito à liberdade de } \\
\text { opinião e expressão; este direito inclui a liberdade de, sem } \\
\text { interferência, ter opinióes e de procurar, receber e trans- } \\
\text { mitir informações e ideias por quaisquer meios e indepen- } \\
\text { dentemente de fronteiras (...)." }\end{array}$ & \\
\hline $\begin{array}{l}\text { "Art. } 20 \text { - Todo ser humano tem direito à liberdade de reu- } \\
\text { nião e associação pacífica." }\end{array}$ & \\
\hline
\end{tabular}

\section{A LEGISLAÇÃO INTERNACIONAL E AÇÕES JURÍDICO-LEGAIS}

Segundo o artigo 4 do Estatuto de Roma (1988), o Tribunal Penal Internacional tem personalidade legal e pode exercer suas funçôes e poderes dentro do território de qualquer estado parte e, por acordo especial, em qualquer outro estado. Quanto à sua jurisdição, o Tribunal atua em crimes de genocídio, crimes contra a humanidade, crimes de guerra ou crimes de agressão, ou seja, atua basicamente em crimes perpetrados pelo estado contra indivíduos.

Myanmar não é signatário do Estatuto, no entanto, em abril de 2018, o Gabinete do Procurador solicitou, baseando-se no artigo 12, parágrafo 2(a), que sua jurisdição se estendesse também ao país, uma vez que Bangladesh é signatário desde 1999 e os crimes contra a humanidade perpetrados pelo governo de Myanmar ocorreram também na fronteira entre os países. Em setembro, o Juízo de Instrução da TPI acatou o pedido da acusação por maioria, dessa forma, o Tribunal passou a ter autorização legal para atuar no estado e julgar quem fosse necessário (TPI, 2018).

No mesmo mês, o Gabinete abriu um exame preliminar relativo à alegada deportação do povo Rohingya de Myanmar à Bangladesh e chegou à conclusão de que há indícios de atos coercitivos que resultaram no deslocamento forçado dessa população. Entre eles, pode-se citar a privação de direitos fundamentais, assassinatos, violência sexual, desapareci- 
mento forçado, destruição e pilhagens, entre outros crimes citados no artigo 7, do Estatuto (TPI, 2018).

Um exame preliminar não é propriamente uma investigação, mas um processo para examinar as informaçốes disponíveis a fim de determinar se há uma base para prosseguir com a investigação de fato. Até o momento, o TPI ainda não abriu o processo de investigação, mas caso o faça e seja provado que o governo de Myanmar cometeu crimes citados no artigo 7 (ESTATUTO DE ROMA, 1988), um inquérito será aberto contra todas as pessoas físicas, sobretudo chefes militares e membros do governo, que participaram ou ordenaram os crimes.

No caso de condenação, o Tribunal poderá impor à pessoa condenada, de acordo com o artigo 77, a pena de prisão até o limite máximo de 30 anos; ou pena de prisão perpétua. Ainda, o condenado pode ter uma multa aplicada; ou perder produtos, bens e haveres provenientes direta ou indiretamente do crime (ESTATUTO DE ROMA, 1988).

$\mathrm{O}$ andamento do inquérito e o cumprimento da pena, em caso de condenação, dependem também da vontade do estado em penalizar as pessoas físicas envolvidas nos crimes, uma vez que a execução das determinações do Tribunal Internacional esbarra nas fronteiras e no princípio da soberania dos estados. No caso de Myanmar, a princípio, é difícil que haja um cumprimento dessas decisóes, uma vez que o país não é signatário do Estatuto e as violaçóes são cometidas e respaldadas por membros da elite política e das forças armadas que ainda estão no poder.

Segundo o ACNUR, desde o dia 25 de agosto de 2018 houve o transporte, por via aérea, de 1500 toneladas de ajuda emergencial avaliada em US\$7,8 milhóes, com o objetivo de auxiliar mais de 250 mil refugiados (ACNUR, 2018).

A continuação da atuação do órgão depende do financiamento dos estados e da doação de pessoas físicas e jurídicas, uma vez que o número de refugiados provenientes de Myanmar continua crescendo. Apesar do plano de repatriamento realizado pelo próprio ACNUR, não há nenhuma indicação de que esse fluxo irá se reverter em um futuro próximo.

Diante desse cenário, não existe perspectiva, até o momento, para a melhora nas condições do povo Rohingya. Além de ser dificultada uma ação mais incisiva por parte do Tribunal Penal Internacional e do ACNUR, devido ao respeito à soberania de Myanmar e à falta de recursos necessários, a não assinatura por parte do país de tratados de direito internacional 
A perseguição ao povo Rohingya e o desrespeito aos direitos humanos em Myanmar

impede uma intervenção legal satisfatória por parte da comunidade internacional, de maneira a resolver a questão.

Como alternativa para a solução pensou-se na ação conjunta no âmbito da Associação de Nações do Sudeste Asiático - ASEAN -. A Declaração de Bangkok, de 1967, deu origem à ASEAN com o objetivo de estabelecer condições para a cooperação e assistência mútua entre os estados-membros. Atualmente Brunei, Cambodja, Indonésia, Laos, Malásia, Myanmar, Filipinas, Singapura, Tailândia e Vietnã são integrantes do bloco e Papua Nova Guiné atua como observador.

A ideia inicial não era a formação de um esquema de integração profundo como na Europa, mas de buscar a cooperação política e a solução de problemas regionais ligados ao subdesenvolvimento e aos problemas sociais característicos desses estados, uma alternativa à influência dos Estados Unidos e da União Soviética em plena Guerra Fria. A Declaração de Bangkok firma o comprometimento entre todos os membros de cooperarem mutuamente entre si com o objetivo de contribuir para a paz, o progresso e a prosperidade da região, além de se fundamentarem em ideais de liberdade, justiça social e bem-estar (MENEZES; PENNA FILHO, 2006).

$\mathrm{O}$ "ASEAN way" consiste em uma série de princípios que conduzem os processos de solução de controvérsias do bloco e as interações entre seus membros. Historicamente, dá uma ênfase excessiva à soberania por conta do passado colonial da região, o que sempre dificultou a resolução de problemas relacionados à violação de direitos humanos (TOBING, 2018).

Outra dificuldade é a preferência pela formação de um consenso, tornando o processo de tomada de decisão lento e o de solução de controvérsias ineficaz. Para Tobing (2018), uma das fraquezas do bloco é deixar de lado os problemas quando não há consenso entre os seus membros.

Dessa forma, para que a questão dos Rohingyas seja resolvida no âmbito da ASEAN, bem como outras semelhantes que possam surgir na região, é necessário que, tratando-se de temas que violem os direitos humanos, eles estejam acima desse princípio de não intervenção e de formação de consenso. Esse tipo de ação violenta dos estados contra sua própria população impõe desafios à projeção internacional e ao crescimento econômico dos países do bloco, uma vez que a integração econômica só pode ser de fato consolidada com a estabilização da região e esta é de extrema importância para o desenvolvimento de Myanmar.

Durante a reunião anual do bloco em 2018, os membros reconheceram o grande número de refugiados como um problema, todavia mostraram-se preocupados em discutir a 
repatriação dos Rohingyas sem garantir que as violações cessassem de fato e que os envolvidos nos crimes fossem levados à justiça. É evidente que a ASEAN pode se tornar um player primordial para a resolução do conflito, desde que modifique seus princípios e adote uma postura mais enfática no sentido de garantir que essas minorias étnicas perseguidas obtenham justi ça e tenham seus direitos assegurados. Sançôes econômicas, o banimento de vistos de viagem a comandantes militares de Myanmar, entre outras açóes que limitem o poder dos envolvidos na perseguição, podem surtir efeitos significativos na resolução de um problema que persiste há décadas (HUMAN RIGHTS WATCH, 2019).

Apresenta-se, todavia, como outra solução possível, a separação territorial de facto entre o estado de Myanmar e um novo estado formado pela população Rohingya. As fronteiras em todo o Raj Britânico durante a administração colonial foram delimitadas por acidentes geográficos. Diversos grupos foram obrigados a conviver no mesmo território e sob a mesma estrutura, fomentando, muitas vezes, disputas entre grupos étnicos, de maneira a exercer controle. Com a independência do país em 1948, o novo governo local buscou manter a unidade nacional, através do diálogo com todas as minorias étnicas, preservando as demarcações realizadas durante o domínio britânico (SHAHABUDDIN, 2019).

Essa decisão encontrava respaldo no direito internacional, que nesse ínterim, ao discutir sobre os novos estados pós-coloniais, redefiniu o conceito de autodeterminação dos povos, conferindo às entidades estatais o direito de uti possidetis juris ${ }^{7}$. Assim, ações separatistas de grupos minoritários não eram vistas como legítimas, uma vez que ameaçavam a recémconquistada soberania dos novos estados formados (SHAHABUDDIN, 2019). A aceitação dessa concepção contribuiu para a eclosão de conflitos étnicos em Myanmar, pois a manutenção das fronteiras do período colonial condicionou a integração forçada no país.

A integração forçada é definida como a ação do estado de obrigar, legalmente, populaçôes étnica, linguística, religiosa e culturalmente diferentes a viverem juntas, sob o pretexto de preservação da "integridade nacional" (HOPPE, 2017). Esse fator leva, concomitantemente, a um processo de aversão da maioria à cultura minoritária, o que passa a justificar as agressões aos direitos do povo Rohingya.

$7 \quad$ O conceito de uti possidetis juris, ao dar o direito de propriedade de um território ao estado que possua um título jurídico sobre ele, se difere do conceito de uti possidetis de facto em que o território pertence aos indivíduos que efetivamente o ocupam, independentemente de a quem pertença seu título jurídico. Dessa maneira, estatiza-se a propriedade, impedindo que os indivíduos possam questionar seu domínio. 
A perseguição ao povo Rohingya e o desrespeito aos direitos humanos em Myanmar

A alternativa de separação territorial defendida nesse artigo foi formulada respeitando o princípio de autodeterminação dos povos de tradição liberal, anterior à redefinição formulada pelos organismos internacionais no pós-Segunda Guerra. Em suma, deriva-se do pressuposto de que uma população não deve ser obrigada a viver com outra. Ludwig von Mises (1944), justifica esse princípio tendo por base a imoralidade, por parte do estado, detentor do monopólio da força, de coagir um povo a viver sob sua autoridade legal. Ainda, considera a consulta popular como maneira eficaz e moral para a resolução dessa questão, uma vez que, os habitantes de uma determinada região devem ter a capacidade de decidir pertencer ou não a determinada entidade estatal.

O principal obstáculo apresentado a esse meio de resolução é a constituição de Myanmar que, além de ter como um de seus pilares a "non-disintegration of the Union" (REPUBLIC OF THE UNION OF MYANMAR, 2008, Chapter 1, Art.6), ainda prevê em um de seus artigos, especificamente, a proibição de movimentos separatistas em qualquer região dentro da união (REPUBLIC OF THE UNION OF MYANMAR, 2008, Chapter 1, Art.10).

A maneira de contornar essa questão seria, primeiramente, a mobilização popular em torno da secessão, conquistando visibilidade internacional e constrangendo o estado nacional. A pressão exercida pela ONU e demais Organizações Internacionais, possível apenas com a adoção do conceito de autodeterminação dos povos de tradição liberal, e sanções econômicas por partes de outros países podem, então, auxiliar nesse processo secessionista.

No entanto, como não há garantia de que tais atores externos apoiarão a região insurgente, existe a iminência de conflito civil, o que ressalta a importância da aceitação por parte do estado do princípio de autodeterminação como única maneira de resolução pacífica (McGEE, 1994). Essa decisão demandaria uma modificação constitucional, no caso, que poderia ser originária da ação de um governante esclarecido ou da cessão à possíveis pressões internas.

\section{CONSIDERAÇÕES FINAIS}

A perseguição ao povo Rohingya não pode ser vista apenas de maneira unilateral, mas como uma conjunção de fatores e atores. Em primeiro lugar, a política de "dividir e governar” do Império Britânico nos séculos XIX e XX criaram as bases para os conflitos étnicos no país, promovendo uma integração forçada. 
Deve-se mencionar, a seguir, o Tatmadaw. Os militares sempre se envolveram nas disputas minoritárias e mantém, até os dias atuais, bastante influência na política e sociedade birmanesas. A preservação dos conflitos étnicos garante ao Tatmadaw uma chance de retornar ao poder após a redemocratização do país em 2008, baseando-se no argumento de necessidade de sua intervenção para a manutenção da ordem.

A elite política, tendo o partido no poder do executivo "National League for Democracy” - NLD -, de Aung San Suu Kyi, como principal representante, exerce, também, importante papel na perpetuação do conflito. Apesar do discurso em favor da tolerância, a exis tência de indivíduos Bamar dentro do partido e suas origens militares justificam, de certa forma, a ausência de ações para a suspensão da perseguição aos Rohingyas. Além disso, o fato de sua base eleitoral ser formada pelo apoio dos monges, muitos deles antimuçulmanos, ao partido auxilia nessa omissão.

Outro importante ator no conflito é a comunidade budista do estado do Rakhine, organizada no partido "Rakhine Nationalities Development Party” - RNDP -. Essa entidade foi acusada de organizar ações de violência étnica contra os Rohingyas em diferentes ocasióes, deixando claro que não os querem no estado.

Por fim, destaca-se o papel de grupos extremistas budistas especificamente o " $\mathrm{Pa}$ triotic Association of Myanmar", mais conhecido como MaBaTha, no conflito. Justificam a perseguição aos Rohingyas partindo da premissa de que a presença do islã em território birmanês é uma ameaça a existência do budismo e, portanto, deve ser combatido. O MaBaTha exerce excessiva influência na política e sociedade birmanesa ao deter o controle sobre a educação religiosa no país. Assim, difundem interpretações completamente antimuçulmanas da doutrina budista, incentivando práticas de discriminação e segregação social e violência étnica.

Tendo em vista o que foi abordado até o momento e considerando que décadas de integração forçada criaram um ambiente hostil em Myanmar para a minoria em questão, a secessão, no geral, se mostra como uma interessante saída, a princípio, ao conceder um território aos Rohingyas, permitindo-lhes plena autonomia e liberdade. No entanto, a configuração do entorno regional e a construção do estado de Myanmar não parecem respaldar essa proposta de resolução na prática.

A configuração do estado birmanês, que permite a separação da sociedade em “raças”, cria as condições necessárias para uma forte centralização de poder, baseada em políticas de controle. Além dos Rohingyas, grupos étnicos como os Karen, os Kachin, os Shan, entre outros, também se defrontam diariamente com políticas de perseguição e marginalização. 
A perseguição ao povo Rohingya e o desrespeito aos direitos humanos em Myanmar

A minoria Karen se mobilizou pela primeira vez em defesa da secessão após a morte de Aung San, porém o movimento foi desmantelado devido a inconsistências internas (CHEESMAN, 2002).

Em oposição aos Rohingyas, em que a grande maioria dos indivíduos se autodeclara muçulmana, os Karen se constituem de budistas, cristãos e adeptos de crenças locais. Sua situação serve como exemplo para demonstrar a existência em Myanmar de conflitos não ape nas contra uma religião específica, mas que atestam o anseio histórico intrínseco a um grupo étnico dominante em exercer pleno domínio sobre a totalidade do território em que se inserem (CHEESMAN, 2002). A utilização de uma retórica Bamar-budista por parte do governo para a criação de uma identidade nacional, nesse caso, funciona como um estratagema para manter a integridade territorial e impedir possíveis movimentos insurgentes, criando subterfúgios para combatê-los sempre que necessário.

Próximo às suas fronteiras, países como a Tailândia e o Paquistão conseguiram conter movimentos separatistas, Sul da Tailândia e Baluchistão, respectivamente. Esses episódios podem, também, contribuir para um desencorajamento do surgimento de outras insurgências secessionistas na região.

Os Rohingyas, ainda, não aparentam demonstrar qualquer interesse voltado à criação de um novo estado. A difusão do ideal de "Raças Nacionais" na sociedade birmanesa, contribui para a manutenção de um sentimento de desejo de pertencimento no povo Rohingya. O que, substancialmente, leva a uma luta por reconhecimento por parte do estado dominante no lugar de uma independência (CHEESMAN, 2017). Por último, a omissão da mídia e da sociedade civil acerca desse tema é evidente, mostrando que os Rohingyas seguirão, por hora, desamparados na luta por seus direitos básicos. 


\section{REFERÊNCIAS BIBLIOGRÁFICAS}

ACNUR. Emergências - Robingyas. ACNUR Brasil, 2019. Disponivel em: https://www.acnur.org/portugues/rohingya/. Acesso em: 6 maio 2019.

ALAM, J. The Current Rohingya Crisis in Myanmar in Historical Perspective. Journal of Muslim Minority Affairs, v. 39, n. 1, p. 1-25, 2019.

ASSEMBLEIA GERAL DAS NAÇÕES UNIDAS. Declaração Universal dos Direitos Humanos. Paris, 10 dez. 1948. Disponível em: https://nacoesunidas.org/wp- content/uploads/ 2018/10/DUDH.pdf. Acesso em: 6 maio 2019

AZAD, A.; JASMIN, F.; Durable solutions to the protracted refugee situation: the case of Rohingyas in Bangladesh. Journal of Indian Research, v. 1, n. 4, p. 25-35, 2013.

CHEESMAN, N. How in Myanmar "national races” came to surpass citizenship and exclude Rohingya. Journal of Contemporary Asia, v. 47, n. 3, p. 461-483, 2017.

CHEESMAN, N. Seeing 'Karen' in the union of Myanmar. Asian Ethnicity, v. 3, n. 2, p. 199220, 2002.

FARZANA, K.F. Memories of Burmese Robingya Refugee: Contested Identity and Belonging. Palgrave Macmillan, 2017.

GUAN, A.C. Political legitimacy in Myanmar: The ethnic minority dimension. Asian Security, v. 3, n. 2, p. 121-140, 2019.

HOPPE, H.H. Democracia, o Deus que falhou. LVM Editora, 2017.

HUMAN RIGHTS COUNCIL. Report of the independent international fact-finding mission on Myanmar. 12 set. 2018. 
A perseguição ao povo Rohingya e o desrespeito aos direitos humanos em Myanmar

HUMANS RIGHT WATCH. ASEAN: Don't Whitewash Atrocities Against Rohingya, 19 jun. 2019. Disponível em: https://www.hrw.org/news/2019/06/19/asean-dont-whitewashatrocities-against-rohingya Acesso em: 28 ago. 2019

LEIDER, J. P. Competing identities and the hybridized history of the Rohingyas. Metamorphosis: Studies in social and political change in Myanmar, p. 151-78, 2015.

McGEE, R.W., Secession Reconsidered. Journal of Libertarian Studies, v. 11, n. 1, p. 11, 1994.

MENEZES, A.M.; PENNA FILHO, P. Integração Regional: os Blocos Econômicos nas Relações Internacionais. Rio de Janeiro: Elsevier, 2006.

MISES, L.V. Omnipotent government. Mises Institute. 1944.

MUKHERJEE, K. Race relations, nationalism and the humanitarian Rohingya crisis in contemporary Myanmar. Asian Journal of Political Science, v. 27, n. 2, p. 235-251, 2019.

MUKHERJEE, K. The Ethnic Minority Question and Rohingya Crisis in Contemporary Myanmar. Journal of Muslim Minority Affairs, v. 39, n. 1, p. 26-43, 2019.

REPUBLIC OF THE UNION OF MYANMAR. Constitution of the Republic of the Union of Myanmar (2008). Naipidau, 2008.

SCHERF, E.L.; GONZALEZ, R.M. Migração forçada e crise humanitária no Mianmar: Rohingya - sem território, sem nação e sem direitos. RICRI, Paraíba, v. 5, n. 10, p. 37-73, 2018.

SHAHABUDDIN, M. Post-colonial Boundaries, International Law, and the Making of the Rohingya Crisis in Myanmar. Asian Journal of International Law, v. 9, n. 2, p. 334-358, 2019.

TOBING, D.H. The Limits and Possibilities of the ASEAN Way: The Case of Ronhingya as Humanitarian Issue in Southest Asia. The 1st International Conference on South East Asia Studies. p. 148-174, 2016. 
TRIBUNAL PENAL INTERNACIONAL. Estatuto de Roma. Roma, 17 jul. 1988. Disponível em: http://pfdc.pgr.mpf.mp.br/atuacao-e-conteudos-de-apoio/legislacao/segurancapublica/estatuto_roma_tribunal_penal_internacional.pdf. Acesso em: 6 maio 2019.

TRIBUNAL PENAL INTERNACIONAL. Preliminary Examination: Rohingya/Myanmar. [S. l.], 8 abr. 2018. Disponível em: https://www.icc-cpi.int/rohingya-myanmar Acesso em: 6 maio 2019 .

WALTON, M.J; HAYWARD, S. Contesting Buddhist Narratives: Democratization, Nationalism and Communal Violence in Myanmar. Policy Studies East-West Center, v. 71, 2014. 